\title{
Effect of a Training Workshop on Oncology Clinicians' Psychoso- cial Care Delivery Self-Efficacy and Perceived Barrier in Nigeria
}

\author{
Chioma Asuzu $^{1,2^{*}}$ and Elizabeth Akin-Odanye ${ }^{3}$ \\ ${ }^{1}$ Department of Counselling and Human Development Studies, University of Ibadan, Ibadan, Nigeria \\ ${ }^{2}$ Department of Radiation Oncology, College of Medicine, University of Ibadan, Ibadan, Nigeria \\ ${ }^{3}$ Department of Clinical Psychology, University College Hospital, Ibadan, Nigeria
}

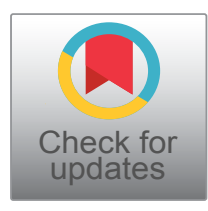

*Corresponding author: Chioma Asuzu, Department of Counselling and Human Development Studies; Department of Radiation Oncology, University of Ibadan, Ibadan, Nigeria

\begin{abstract}
Psychosocial care is an important part of a multidisciplinary approach to cancer management to mitigate the experience of distress often reported among those affected by cancer. Not many specialists are available in Nigeria to detect and address psychosocial distress in cancer patients.
\end{abstract}

Objectives: This study was designed to assess the effect and the sustainability of the effect of a training workshop on the psychosocial care delivery self-efficacy and perceived barrier among oncology clinicians in Nigeria.

Methods: Participants in this study were 33 oncology clinicians from 17 institutions across 13 states in Nigeria who took part in a 3-day psychosocial oncology training workshop. Participants completed both pre and post workshop tests on self-efficacy and perceived barrier in psychosocial service delivery to oncology patients.

Results: A significant improvement was observed in their psychosocial care delivery self-efficacy $((t=-6.318 ; p<$ $0.05)$ and significant reduction was observed in their perceived barrier $(t=3.280 ; p<0.05)$ to providing psychosocial care to cancer patients at the end of the workshop. At three months follow up, the significant improvement in self-efficacy was maintained $(t=-5.327 ; p<0.05)$ while the significant reduction in perceived barriers $(t=0.584 ; p>0.05)$ was lost.

Conclusion: It was concluded that our psychosocial training workshop was effective in the short and long-term for improving psychosocial care delivery self-efficacy. It is thus recommended that such training should be ongoing to ensure that its effect on reducing perceived barrier is sustained.

\section{Keywords}

Oncology, Training, Psychosocial, Self-efficacy, Perceived barrier, Service, Nigeria

\section{Background}

Psychosocial care in oncology is concerned with the understanding and treatment of the social, psychological, emotional, spiritual and functional aspects of life with cancer, at all stages of the disease trajectory from prevention through to bereavement [1]. Research suggests that $35-50 \%$ of cancer patients meet the criteria for a psychiatric diagnosis such as depression, anxiety or clinically significant emotional distress [2]. Physicians and indeed all clinicians caring for patients with cancer are increasingly being expected to evolve structures that enhance patients-clinicians' communication around both patients' disease and treatment concerns as well as psychosocial issues [3].

There are however some potential barriers to communicating psychosocial issues during consultations at both organizational and individual levels [4] resulting in under-recognition of psychosocial problems and hence inadequate referrals to supportive services [5-7]. Such barriers could include oncologists' belief that psychosocial management is burdensome and not congruent with their practice styles, perceived limited consultation time, attempt to avoid emotional strain, concerns about potential patient stigma, insufficient knowledge about diagnostic criteria or services to which patients may be referred [8-10]. At the organizational level, barriers may include stifling policies on employment of specialists, procurement of drugs, and provision of psychotherapeutic care as well as absence of standard structure for systematically identifying and managing

Citation: Asuzu C, Akin-Odanye E (2020) Effect of a Training Workshop on Oncology Clinicians' Psychosocial Care Delivery Self-Efficacy and Perceived Barrier in Nigeria. Int J Cancer Clin Res 7:133. doi. org/10.23937/2378-3419/1410133

Accepted: March 24, 2020; Published: March 26, 2020

Copyright: (C) 2020 Asuzu C, et al. This is an open-access article distributed under the terms of the Creative Commons Attribution License, which permits unrestricted use, distribution, and reproduction in any medium, provided the original author and source are credited. 
patients with psychosocial problems [4].

Interventions aimed at improving health care service providers' psychosocial care delivery in oncology settings have frequently included communication training component to improve healthcare providers' knowledge, confidence and psychosocial orientation [11-13]. A key component of most behavior change interventions is self-efficacy which is a task-specific construct linked to persons' confidence and beliefs in their ability to succeed in a given task [14]. The expectation was that the higher individual's self-efficacy is, the more likely it is that the individual will engage in a behavior and succeed [14]. Studies on self-efficacy in cancer settings have typically focused on promoting self-care among cancer patients [15]. There is a dearth of literature on training to enhance psychosocial care self-efficacy among oncology clinicians.

Nigeria, a poor resource economy with poorly funded healthcare system has a huge cancer burden with an estimated 115,950 new cancer cases diagnosed in 2018 [16]. In the face of high load of cancer patients with majority having late stage disease, the provision of appropriate psychosocial services for cancer patients or referral to support services is often not a priority in our setting due to inadequate resources and limited manpower in the field. The importance of training non-mental healthcare professionals to offer psychological support to people with cancer is becoming increasingly recognized. Hence the study reported herein sought to fill this important gap by providing training in the area of psychosocial care delivery for oncology clinicians working in Nigeria to promote their self-efficacy in identifying and addressing cancer-related distress in patients.

\section{Objectives of the Study}

A broad objective of this study was to build capacity in the area of psychosocial care delivery for cancer patients in oncology settings in Nigeria. Specifically, the study seeks to:

1. Assess the effect of a training workshop on oncology clinician's psychosocial care delivery self-efficacy

2. Ascertain the effect of a training workshop on oncology clinicians perceived barriers to psychosocial service delivery

3. Determine the sustainable effect of a training workshop on oncology clinicians' self-efficacy and perceived barrier in psychosocial service delivery over a follow up period.

\section{Hypothesis}

1. It is hypothesized that at the end of the training workshop there will be a sustained significant improvement in the oncology clinicians psychosocial care delivery self-efficacy in oncology settings in $\mathrm{Ni}$ geria.

2. It is hypothesized that at the end of the training workshop there will be a sustained significant reduction in the oncology clinicians perceived barrier to psychosocial care delivery in oncology settings in Nigeria.

\section{Methodology}

This study is a pre-test, post-test, single group experimental (prospective) study. The respondents in this study were 33 clinicians working with oncology patients from 17 different hospitals from across 13 states in $\mathrm{Ni}$ -

Table 1: Showing institutions represented at the workshop.

\begin{tabular}{|l|l|l|}
\hline $\mathbf{S} / \mathbf{N}$ & State & Institution \\
\hline $\mathbf{1}$ & Osun State & Obafemi Awolowo University Teaching Hospital Complex, (OAUTHC), Ile-Ife \\
\hline $\mathbf{2}$ & Ekiti State & Ekiti State University (EKSUTH), Ado-Ekiti, Ekiti State \\
\hline $\mathbf{3}$ & Oyo State & University College Hospital (UCH), Ibadan, Oyo State \\
\hline $\mathbf{4}$ & Oyo State & University of Ibadan, Ibadan, Oyo State \\
\hline $\mathbf{5}$ & Oyo State & Ladoke Akintola University of Technology (LAUTECH), Ogbomoso, Oyo State \\
\hline $\mathbf{6}$ & Lagos state & St Nicholas Hospital, Lagos, Lagos State \\
\hline $\mathbf{7}$ & Ogun State & Federal Medical Centre (FMC), Abeokuta, Ogun State \\
\hline $\mathbf{8}$ & Ondo State & University of Medical Sciences, Ondo, Ondo State \\
\hline $\mathbf{9}$ & Gombe State & Federal Teaching Hospital (FTH), Gombe, Gombe State \\
\hline $\mathbf{1 0}$ & Imo State & Federal Medical Centre (FMC), Owerri, Imo State \\
\hline $\mathbf{1 1}$ & Enugu State & University of Nigeria Teaching Hospital (UNTH), Enugu, Enugu State \\
\hline $\mathbf{1 2}$ & Enugu State & Calvary Hospice and Palliative Care Center, Enugu, Enugu state \\
\hline $\mathbf{1 3}$ & Benue State & Benue State University (BSU), Makurdi, Benue State \\
\hline $\mathbf{1 4}$ & Benue State & Federal Medical Centre (FMC), Makurdi, Benue State \\
\hline $\mathbf{1 5}$ & Bauchi State & General Hospital Ningi, Bauchi State \\
\hline $\mathbf{1 6}$ & Bauchi State & Abubakar Tafawa Balewa University Teaching Hospital (ATBUTH), Bauchi State \\
\hline $\mathbf{1 7}$ & Cross River State & University of Calabar Teaching Hospital (UCTH), Calabar, Cross River State \\
\hline & & \\
\hline
\end{tabular}


geria (see Table 1). They participated in psychosocial oncology training workshop that took place in the University College Hospital, Ibadan, and Southwest Nigeria.

\section{Procedure}

A call to participate in a three-day psychosocial oncology training workshop was sent via the post and electronically to hospitals for personnel working with cancer patients to register their intents to participate. A total of 64 applicants sent in letters of intent to participate in the workshop from different institutions across the country. 46 of the 64 applicants met the eligibility criteria and were sent a formal letter of invitation to attend. Only 33 of the eligible applicants were able to attend the training.

At the training, baseline assessments of psychosocial care delivery self-efficacy and perceived barriers to psychosocial communication were collected. The training sessions comprised topics related to both theoretical and practical aspects of psychosocial care in oncology. Topics covered included overview of cancer burden in Nigeria, cancer specific psychosocial issues, patient-clinician communication, oncology clinician's self-care, screening and assessment for distress, distress management and setting up psycho-oncology service. Posttest assessment was done immediately after the training as well as at 3, 6 and 9 months afterwards via email correspondence. However only 9, 7 and 12 oncology clinicians completed and returned the questionnaires sent to them at 3 , 6 , and 9 months follow up respectively out of the 33 that participated in the training.

\section{Measures}

An 8-item Oncology Clinicians Psychosocial Care Delivery Self-Efficacy questionnaire was developed and piloted by the researchers. The instrument has a 4-point response format of 'Not sure', 'Somewhat sure', 'Sure' and 'Very sure'. Higher scores indicate higher self-efficacy in providing psychosocial care to cancer patients. The instrument yielded a Croncbach's alpha of 0.771 indicating its reliability.

The 11-item Perceived Barriers against Psychosocial Communication questionnaire [17] was used in assessing oncology clinician's perceived barriers to psychosocial care delivery. The instrument has a 4-point response format of 'Strongly Agree', 'Agree', 'Disagree' and 'Strongly Disagree'. Higher scores on the questionnaire indicate higher perceived barriers. When pilot tested for reliability within our setting, it yielded a Cronbach's alpha of 0.733

Demographic information such as age, gender, highest academic qualification, profession, years and spent working with cancer patients were also collected (see Table 2).

\section{Data analysis}

Obtained data were analyzed on IBM SPSS 21 using frequency counts and percentages as well as Paired Samples T-test.

\section{Results}

Participants had an age range of 21-64 with a mean age of $41.16 \pm 9.535$. Their other characteristics

Table 2: Respondents' demographic and work characteristics.

\begin{tabular}{|c|c|c|c|}
\hline Characteristics & Freq/(\%) & Characteristics & Freq/(\%) \\
\hline Gender & & Multidisciplinary cancer team member & \\
\hline Male & $14(42.4 \%)$ & Yes & $20(60.6 \%)$ \\
\hline Female & $19(57.6 \%)$ & No & $13(39.4 \%)$ \\
\hline Education & & Work setting & \\
\hline First degree & $16(48.5 \%)$ & Hospital & $26(78.8 \%)$ \\
\hline MSc. & $11(33.3 \%)$ & University & $4(12.1 \%)$ \\
\hline \multirow[t]{2}{*}{ Not indicated } & $6(18.2 \%)$ & Hospital and University & $2(6.1 \%)$ \\
\hline & & Not indicated & $1(3.0 \%)$ \\
\hline Profession & & Years in cancer work & \\
\hline Physicians & $8(24.2 \%)$ & 0 & $1(3.0 \%)$ \\
\hline Nursing & $8(24.2 \%)$ & $1-3$ years & $7(21.2 \%)$ \\
\hline Social worker & $6(18.2 \%)$ & 4-6 years & $9(27.2 \%)$ \\
\hline Clinical psychologist & $3(9.2 \%)$ & $7-9$ years & $5(15.2 \%)$ \\
\hline Counsellor & $1(3.0 \%)$ & $10-15$ years & $2(6.1 \%)$ \\
\hline Patient navigator & $5(15.1 \%)$ & $>15$ years & $3(9.1 \%)$ \\
\hline Pharmacist & $1(3.0 \%)$ & Not indicated & $6(18.2 \%)$ \\
\hline \multirow[t]{3}{*}{ Medical laboratory scientist } & $1(3.0 \%)$ & Previous psycho-oncology training & \\
\hline & & Yes & $10(30.3 \%)$ \\
\hline & & No & $23(69.7 \%)$ \\
\hline
\end{tabular}


are presented on Table 2.

Table 2 indicates that slightly more women (57.6\%) than men participated in the study, majority of the respondents had a first degree $(48.5 \%)$ and most were physicians and nurses (24.2\% each). The table also shows that $84.9 \%$ of the respondents work in hospital settings, majority had worked with cancer patients for between 4 and 6 years (27.2\%). Most of them were members of a multidisciplinary cancer team (60.6\%) and majority had no previous training in psycho-oncology (69.7\%).

Table 3 shows that there is a significant improvement in the oncology clinicians psychosocial care delivery self-efficacy immediately following intervention, at 3 months and at 9 months $(p<0.01)$ but not at 6 months $(p>0.05)$. Hence the hypothesis that there will be a significant sustainable improvement in oncology clinicians' psychosocial care delivery self-efficacy following intervention is partially accepted.

Table 4 shows that there is a significant reduction in the oncology clinicians perceived barriers psychosocial care delivery immediately following intervention ( $p<0.01)$. The significant reduction was however not sustained at 3, 6 and 9 months ( $p>0.05$ ). Hence the hypothesis that there will be a significant sustained reduction in oncology clinicians' perceived barrier to psy- chosocial care delivery is rejected.

\section{Discussion}

In this study we set out to determine the effect of a psychosocial training workshop on oncology clinicians' psychosocial care delivery self-efficacy and perceived barriers in oncology settings in Nigeria. Immediately following the three-day workshop, there was a significant improvement in the oncology clinicians' self-efficacy and significant decrease in their perceived barrier to providing psychosocial care to cancer patients.

The significant decrease in perceived barrier to providing psychosocial care to cancer patients was however not sustained beyond immediately following intervention. Barriers to psychosocial care in oncology are often multileveled - organizational, cultural and individual clinician-related level [18]. While the clinicians may have perceived these barriers as surmountable immediately following intervention, the reality of the challenges in their day-to-day clinical practice may have caused a change in their perception. There is less emphasis on psychosocial care and support for cancer patients in most hospitals in our setting hence the structure with which to provide the service is often lacking. Comprehensible routes for psychosocial assessment and treatment are needed to reduce organizational and individual barriers

Table 3: Paired Samples Test of effect of training on oncology clinicians' psychosocial care delivery self-efficacy at follow-up.

\begin{tabular}{|c|c|c|c|c|c|c|c|c|c|}
\hline & & \multicolumn{5}{|c|}{ Paired Differences } & \multirow{3}{*}{$\mathbf{T}$} & \multirow{3}{*}{ df } & \multirow{3}{*}{ Sig. } \\
\hline & & \multirow[t]{2}{*}{ Mean } & \multirow[t]{2}{*}{ Std. Dev. } & \multirow{2}{*}{$\begin{array}{l}\text { Std. } \\
\text { Error } \\
\text { Mean }\end{array}$} & \multicolumn{2}{|c|}{$\begin{array}{l}95 \% \text { Confidence } \\
\text { Interval of the } \\
\text { Difference }\end{array}$} & & & \\
\hline & & & & & Lower & Upper & & & \\
\hline Pair 1 & $\begin{array}{l}\text { Pretest - Postest psychosocial } \\
\text { care delivery self-efficacy }\end{array}$ & -5.594 & 5.009 & 0.885 & -7.4 & -3.788 & -6.318 & 31 & 0.000 \\
\hline Pair 2 & $\begin{array}{l}\text { Pretest - } 3 \text { months Postest } \\
\text { psychosocial care delivery self- } \\
\text { efficacy }\end{array}$ & -4 & 2.291 & 0.764 & -5.8 & -2.239 & -5.237 & 8 & 0.000 \\
\hline Pair 3 & $\begin{array}{l}\text { Pretest - } 6 \text { months Postest } \\
\text { psychosocial care delivery self- } \\
\text { efficacy }\end{array}$ & -3.833 & 5.776 & 2.358 & -9.9 & 2.229 & -1.626 & 5 & 0.165 \\
\hline Pair 4 & $\begin{array}{l}\text { Pretest - } 9 \text { months Postest } \\
\text { psychosocial care delivery self- } \\
\text { efficacy }\end{array}$ & -5.75 & 4.181 & 1.207 & -8.4 & -3.094 & -4.765 & 11 & 0.000 \\
\hline
\end{tabular}

Table 4: Paired Samples Test of effect of training on oncology clinicians' perceived barriers to psychosocial care delivery at follow-up.

\begin{tabular}{|c|c|c|c|c|c|c|c|c|c|}
\hline & & \multicolumn{5}{|c|}{ Paired Differences } & \multirow[t]{3}{*}{$\mathbf{T}$} & \multirow[t]{3}{*}{ df } & \multirow[t]{3}{*}{ Sig. } \\
\hline & & \multirow[t]{2}{*}{ Mean } & \multirow[t]{2}{*}{$\begin{array}{l}\text { Std. } \\
\text { Dev. }\end{array}$} & \multirow[t]{2}{*}{$\begin{array}{l}\text { Std. } \\
\text { Error } \\
\text { Mean }\end{array}$} & \multicolumn{2}{|c|}{$\begin{array}{l}\text { 95\% Confidence } \\
\text { Interval of the } \\
\text { Difference }\end{array}$} & & & \\
\hline & & & & & Lower & Upper & & & \\
\hline Pair 1 & Pretest - Posttest perceived barrier & 2.938 & 5.067 & 0.896 & 1.111 & 4.764 & 3.280 & 31 & 0.003 \\
\hline Pair 2 & Pretest - 3 months posttest perceived barrier & 1.111 & 5.711 & 1.904 & -3.278 & 5.501 & 0.584 & 8 & 0.575 \\
\hline Pair 3 & Pretest - 6 months posttest perceived barrier & 4.000 & 7.043 & 2.875 & -3.391 & 11.391 & 1.391 & 5 & 0.223 \\
\hline Pair 4 & Pretest - 9 months posttest perceived barrier & 1.000 & 5.865 & 1.768 & -2.940 & 4.940 & 0.565 & 10 & 0.584 \\
\hline
\end{tabular}


as well as promote organizational cultures that value the need to incorporate psychosocial care in usual medical care of cancer patients.

At three months the significant improvement in the clinicians' psychosocial care delivery self-efficacy was sustained but lost at six months. This is comparable to the findings of other studies among therapists where initial improvements were reported in therapist skill following the completion of a workshop but skills decreased over time, and were comparable to those in the untrained therapist group four months post training [19-21].

However, at 9 months the significant improvement in the clinicians' psychosocial care delivery self-efficacy was regained. While this pattern is not commonly seen in literature, a possible explanation for the pattern in our study was the annual psycho-oncology workshop/ conference that was organized in July 2018 after the 6 months follow up survey had been collected. Some of the participants at the psychosocial oncology training workshop also attended the workshop/conference and that may account for the re-emerging significant increase in their self-efficacy at 9 months. This also seems to underscore the importance of periodic psychosocial oncology training in building clinicians' confidence in providing psychosocial services to cancer patients.

The results from this study can only be said to give a preliminary evidence of the impact of the psychosocial oncology training workshop on improving self-efficacy and reducing perceived barriers in oncology clinicians' provision of psychosocial services.

\section{Limitation}

A major limitation of this study is the high attrition rate. This limitation occurred despite attempts to remind the participants via different media (calls, text and WhatsApp messages) to complete the follow-up survey sent to their emails. This is highly instructive for future studies considering collecting follow-up data via emails in our setting. This limitation did not however detract the valuable contribution of the study.

\section{Conclusion}

Our psychosocial training workshop was effective in the short and long-term for improving psychosocial care delivery self-efficacy of oncology clinicians. It is thus recommended that such training should be ongoing to ensure that its effect on reducing perceived barrier is sustained on the long run.

\section{Acknowledgement}

Tertiary Education Trust fund (NIGERIA) TETFUND for providing the grant for this research.

\section{References}

1. (1999) Canadian Association of Psychosocial Oncology Standards Toronto: CAPO.
2. Thalén-Lindström A, Larsson $G$, Glimelius $B$, Johansson B (2013) Anxiety and depression in oncology patients; A longitudinal study of a screening, assessment and psychosocial support intervention. Acta Oncologica 52: 118-127.

3. Stobo JD, Kohen JJ, Kimball HR, LaCombe MA, Schechter GP, et al. (1995) Project Professionalism, Philadelphia: American Board of Internal Medicine.

4. Grimshaw JM, Eccles MP, Walker AE, Thomas RE (2002) Changing physicians' behavior: What works and thoughts on getting more things to work. J Contin Educ Health Prof 22: $237-243$.

5. Rogers M, Todd C (2002) Information exchange in oncology outpatient clinics: Source, valence and uncertainty. Psychooncology 11: 336-345.

6. Fallowfield L, Ratcliffe D, Jenkins V, Saul J (2001) Psychiatric morbidity and its recognition by doctors in patients with cancer. Br J Cancer 84: 1011-1015.

7. Cull A, Stewart M, Altman D (1995) Assessment of and intervention for psychosocial problems in routine oncology practice. Br J Cancer 72: 229-235.

8. Schofield P, Carey M, Bonevski B, Sanson-Fisher R (2006) Barriers to the provision of evidence-based psychosocial care in oncology. Psychooncology 15: 863-872.

9. Wein S, Sulkes S, Stemmer S (2010) The oncologist's role in managing depression, anxiety, and demoralization with advanced cancer. Cancer J 16: 493-499.

10. McLean M, Cleland J, Worrell M, Vögele C (2011) "What am I going to say here?" The experiences of doctors and nurses communicating with patients in a cancer unit. Front Psychol 2: 339.

11. Merckaert I, Libert Y, Razavi D (2005) Communication skills training in cancer care: Where are we and where are we going? Curr Opin Oncol 17: 319-330.

12. Van der Meulen N, Jansen J, Van Dulmen S, Bensing J, van Weert J (2008) Interventions to improve recall of medical information in cancer patients: A systematic review of the literature. Psychooncology 17: 857-868.

13. Wilkinson S, Perry R, Blanchard K, Linsel IL (2008) Effectiveness of a three-day communication skills course in changing nurses' communication skills with cancer/palliative care patients: A randomised controlled trial. Palliat Med 22: $365-375$.

14. Bandura A (1997) Self-efficacy: The exercise of control. New York: Freeman.

15. Borjalilu S, Kaviani A, Helmi S, Karbakhsh M, Mazaheri $M$ (2017) Exploring the role of self-efficacy for coping with cancer: A systematic review. Archives of Breast Cancer 4: 42-57.

16. Ferlay J, Ervik M, Lam F, Colombet M, Mery L, (2018). Global Cancer Observatory: Cancer Today. Lyon, France: International Agency for Research on Cancer.

17. Fagerlind H, Kettis A, Glimelius B, Ring L (2013) Barriers Against Psychosocial Communication: Oncologists' Perceptions. J Clin Oncol 31: 3815-3822.

18. Dilworth S, Higgins I, Parker V, Kelly B, Turner J (2014) Patient and health professional's perceived barriers to the delivery of psychosocial care to adults with cancer: A systematic review. Psycho-Oncology 23: 601-612.

19. Miller WR, Yahne CE, Moyers TB, Martinez J, Pirritano M (2004) A randomized trial of methods to help clinicians learn motivational learning. Journal of Consulting and Clinical Psychology 72: 1050-1062. 
20. Moyers TB, Manuel JK, Wilson PG, Hendrickson SML, Talcott W, et al. (2008) A randomized trial investigating training in motivational interviewing for behavioral health providers. Behavioural and Cognitive Psychotherapy 36: 149-162.
21. Chagnon F, Houle J, Marcoux I, Renaud J (2007) Control-Group study of an intervention training program for youth suicide prevention. Suicide and Lifethreatening Behavior 37: 135-144. 